\title{
A systematic review of the evidence base for the Lightning Process
}

P Parker (a)*, J Aston (b), L de Rijk (b)

a School of Psychology, London Metropolitan University, 166-220 Holloway Rd, N7 8DB b Kings College London

\section{Abstract}

\section{Background}

The Lightning Process (LP), a mind-body training programme, has been applied to a range of health problems and disorders. Studies and surveys report a range of outcomes creating a lack of clarity about the efficacy of the intervention.

\section{Objective}

This systematic review evaluates the methodological quality of existing studies on the LP and collates and reviews its reported efficacy.

\section{Data sources}

Five databases, PsycINFO, PubMed, CINAHL, Embase, ERIC (to September 2018), and Google and Google Scholar were searched for relevant studies.

\section{Study Selection}

Studies of the LP in clinical populations published in peer-reviewed journals or in grey literature were selected. Reviews, editorial articles and studies/surveys with un-reported methodology were excluded.

\section{Data extraction}

Searches returned 568 records, 21 were retrieved in full text of which 14 fulfilled the inclusion criteria (ten quantitative studies/surveys and four qualitative studies). 


\section{Data synthesis and Conclusions}

The review identified variance in the quality of studies across time; earlier studies demonstrated a lack of control groups, a lack of clarity of aspects of the methodology and potential sampling bias. Although it found a variance in reported patient outcomes, the review also identified an emerging body of evidence supporting the efficacy of the LP for many participants with fatigue, physical function, pain, anxiety and depression. It concludes that there is a need for more randomised controlled trials to evaluate if these positive outcomes can be replicated and generalised to larger populations.

\section{Keywords}

Lightning Process

Systematic review

Patient outcomes

\section{Introduction}

The Lightning Process (LP) is a mind-body training programme hypothesised to help individuals to develop a more conscious influence on their neurological function and affect change in physiological processes. 1

To provide ease of access, the program is delivered via a $4 \mathrm{hr}$ audio home-study program with $1 \mathrm{hr}$ of phone coaching, as preparation for the 3 training seminars (4 hr each) with a registered practitioner, which are delivered face to face or online with 3-8 attendees. It was devised in a similar way to other novel approaches, such as Motivational Interviewing,2 through an iterative process of practice-based evidence 3 and qualitative inquiries into clients' experience, and its name was suggested by reports of the rapidity of change, as noted subsequently by participants in other studies.4 It was developed from concepts from Positive Psychology, health education theory, mindfulness, osteopathy, coaching and Neuro-Linguistic Programming (NLP).

It has two phases 1) teaching core concepts and 2) adopting practical tools. In phase 1, participants are presented with relevant theory and research to understand how the mind-body connection can be utilised in order to influence physiology.5 Particular attention is paid to how language can affect neural pathways 1,6 and the role that patient activation and empowerment, 7,8 chronic stress and response expectancy have on physiology.9,10 In phase 2 participants learn a set of steps to a) detect disempowering language, negative expectancies 
and changes in physiology 11; b) pause by employing an interruptive 'stop' process 12,13 and c) make an active choice to employ a set of self-coaching interventions. The self-coaching includes developing self-compassion 14 and a series of questions designed to identify immediate goals and desired physiological states (to replace those identified in step a). The process is completed by the savouring of positive memories 15 that recall previous experiences of those goals and states, combined with the use of body movements and voice tone and speed,16,17 congruent with those memories, to encourage improved physiology.

It has been applied to a range of issues, e.g. Multiple Sclerosis, Chronic Fatigue Syndrome/Myalgic Encephalomyelitis (CFS/ME), Complex Regional Pain Syndrome, Chronic Pain and Fibromyalgia, as well as a range of emotional and cognitive issues such as anxiety, depression, dyslexia and dyspraxia.1,18 It has grown, from its inception in the UK in 1999, to be available in 16 countries and by 2018 had been used by over 23,000 participants. 1

Early anecdotal reports of positive outcomes from some participants and poor outcomes from others 19 resulted in differing perceptions of the LP's efficacy. These reports led to a research interest in the approach, although early investigations used a variety of research methods, producing highly varied reports of efficacy and resulting in a lack of clarity amongst stakeholders as to the intervention's value.

The absence of an overview of these studies results and detailed objective commentary on the quality of each study has further contributed to this lack of clarity.

This systematic review aims to resolve this by examining the quality of the evidence base, the studies' designs and by reviewing the reported efficacy of the intervention. It contextualises and explores the studies' contribution to understanding the efficacy of the intervention, and using a descriptive narrative 20 provides a synthesis of the research outcomes, its limitations and suggestions for future research.

\section{Methods}

The protocol for this review was registered with Prospero21 reference: CRD42018104336 and this report conforms to the recommendations from the Preferred Reporting Items for Systematic Reviews and Meta-Analyses statement (PRISMA)22 (see Fig. 1). 
1. Download: Download high-res image (402KB)

2. Download: Download full-size image

Fig. 1. PRISMA 2009 Flow Diagram for Systematic Review.

Search strategy

Five electronic reference databases (PsycINFO, PubMed, CINAHL, Embase, ERIC) were searched for the phrase "Lightning Process" in all fields/text. In addition, the authors also conducted manual searches in Google Scholar and Google. The search terms used for this were "Lightning Process" and "Lightning Process" AND 'study' OR 'survey' OR 'health'. No date limit was set and articles in all languages were included.

Selection criteria and study selection

The selection criteria are collated in Table 1. Quantitative studies and surveys, including those with cross-sectional designs, qualitative studies and mixed methods studies specific to the Lightning Process intervention published in peerreviewed journals and grey literature were included. Results were required to 
include relevant uses of the phrase 'Lightning Process' that referred to studying this intervention and records that did not meet this criterion were excluded (e.g.; Production of perchlorate by laboratory simulated lightning process; the lightning process in thunderstorms).

Table 1. Selection criteria.

\section{P Population using the Lightning Process}

I Lightning Process

C NA

O Identify research studying this intervention

Cross-sectional designs, qualitative studies and surveys and mixed methods studies published in

$S$ peer-reviewed journals.

Non-peer reviewed articles on surveys or outcome measures studies with a reported methodology.

The Google searches produced over 42,000, mostly non-relevant results, and issue noted by others.23,24 Therefore, the evaluation was limited to the first 70 results, which provided an adequate buffer to capture key relevant results.

Duplicate records were removed and additional records were searched for in the references of the selected records.

\section{Search results}

The reference database searches provided a small set of results (PsycINFO = one, PubMed = eight, $\mathrm{CINAHL}=$ eight, Embase $=$ eight, ERIC $=$ nine). With the addition of Google and Google Scholar searches a further 560 results were returned.

Six studies were identified from the references of these results and 32 duplicates were removed. This produced a total of 568 records (see Fig. 1) with 21 records identified as potentially eligible and retrieved in full text. Seven studies did not evaluate the LP and were excluded, resulting in a total of 14 studies meeting the inclusion criteria.

\section{Data collection, analysis and quality assessment}

Two authors (PP, JA) read and re-read the papers in their entirety and assessed the methodological quality of the selected studies dependent on the study type as suggested by other researchers.25., 26., 27., 28., 29. For evaluating the qualitative studies four review areas (1. Phenomenon studied and context; 2. Ethics; 3 Data collection, analysis and potential researcher bias; 4. Policy and practice implications) suggested by Long and Godfrey 30 were used. The quantitative studies were assessed with the $\mathrm{NIH}$ study quality assessment 
tools, 31 and the five criteria (1. Clarity of aims and objectives; 2. Appropriateness of research design; 3 . Clarity of research process; 4 . Relationship of data to results; 5 . Appropriateness of method of analysis) identified by DixonWoods25 were used for quantitative surveys.

Any areas identified by these tools as possible sources of bias were evaluated as to their potential effect on the results reported. Following the suggestion by Dixon-Woods 25 to capture the maximum data for review, any rated as 'poor' were to remain within the review but be identified as such in the analysis. Although all 14 studies passed this assessment (see Table 2) potential limitations were identified, which are detailed in the limitations section.

Table 2. Overview of studies.

\begin{tabular}{|c|c|c|c|c|c|c|c|}
\hline Author/Year & Title & Country & Method & $\begin{array}{l}\text { Peer } \\
\text { reviewed/ } \\
\text { controlled } \\
\text { (PR/C) }\end{array}$ & $\mathbf{N}$ & $\begin{array}{l}\text { Age } \\
\text { group }\end{array}$ & Quality \\
\hline Finch, 2010 & $\begin{array}{l}\text { LP Snapshot Survey of } \\
\text { clients' experiences }\end{array}$ & INTL & Survey & $x$ & 1297 & $\begin{array}{l}\text { Not } \\
\text { reported }\end{array}$ & Fair \\
\hline $\begin{array}{l}\text { ME } \\
\text { association, } \\
2010\end{array}$ & Managing my M.E & UK & Survey & $x$ & 4217 & All & Fair \\
\hline $\begin{array}{l}\text { Sussex \& Kent } \\
\text { ME/CFS } \\
\text { Society, } 2010\end{array}$ & ME/CFS Patients Survey & UK & Survey & $x$ & 457 & $\begin{array}{l}\text { Not } \\
\text { reported }\end{array}$ & Fair \\
\hline $\begin{array}{l}\text { FOnneb0 et al., } \\
2012\end{array}$ & $\begin{array}{l}\text { Worst Cases Reported to } \\
\text { the NAFKAM } \\
\text { International Registry of } \\
\text { exceptional Courses of } \\
\text { disease }\end{array}$ & Norway & Case report & $x$ & 5 & $\begin{array}{l}\text { Not } \\
\text { reported }\end{array}$ & Good \\
\hline $\begin{array}{l}\text { Sandaunet \& } \\
\text { Salamonsen, } \\
2012\end{array}$ & $\begin{array}{l}\text { CFE-/ME-pas i enters } \\
\text { ulike erfaringer med } \\
\text { Lightning Process. }\end{array}$ & Norway & Qualitative & PR & 22 & Adult & Good \\
\hline $\begin{array}{l}\text { Bringsli et al., } \\
2013\end{array}$ & $\begin{array}{l}\text { The Norwegian ME } \\
\text { Association national } \\
\text { survey }\end{array}$ & Norway & Survey & $x$ & 1096 & All & Fair \\
\hline \multirow[t]{2}{*}{ Finch, 2013} & Outcome measures study & UK & Quantitative & $x$ & 205 & All & Good \\
\hline & $\begin{array}{l}\text { Experiences of young } \\
\text { people who have }\end{array}$ & UK & Qualitative & PR & 9 & & Good \\
\hline $\begin{array}{l}\text { Reme, Archer } \\
\text { \& Chalder, } \\
2013 .\end{array}$ & $\begin{array}{l}\text { undergone the Lightning } \\
\text { Process to treat chronic } \\
\text { fatigue syndrome/myalgic } \\
\text { encephalomyelitis - a } \\
\text { qualitative study. }\end{array}$ & & & & & $\begin{array}{l}\text { Adolescen } \\
\mathrm{t}\end{array}$ & \\
\hline $\begin{array}{l}\text { Crawley et al., } \\
2013\end{array}$ & $\begin{array}{l}\text { The feasibility and } \\
\text { acceptability of } \\
\text { conducting a trial of } \\
\text { specialist medical care } \\
\text { and the Lightning Process } \\
\text { in children with chronic } \\
\text { fatigue syndrome: } \\
\text { feasibility randomized } \\
\text { controlled trial (SMILE }\end{array}$ & UK & Qualitative & PR & 56 & $\begin{array}{l}\text { Adolescen } \\
\mathrm{t}\end{array}$ & Good \\
\hline
\end{tabular}




\begin{tabular}{|c|c|c|c|c|c|c|c|}
\hline Author/Year & Title & Country & Method & $\begin{array}{l}\text { Peer } \\
\text { reviewed/ } \\
\text { controlled } \\
(\mathrm{PR} / \mathrm{C})\end{array}$ & $\mathbf{N}$ & $\begin{array}{l}\text { Age } \\
\text { group }\end{array}$ & Quality \\
\hline & study) & & & & & & \\
\hline Finch, 2014 & $\begin{array}{l}\text { Lightning Process \& } \\
\text { Multiple Sclerosis: Proof } \\
\text { of Concept Study }\end{array}$ & UK & $\begin{array}{l}\text { Proof of } \\
\text { Concept }\end{array}$ & $x$ & 11 & Adult & Fair \\
\hline $\begin{array}{l}\text { Hagelsteen \& } \\
\text { Moen Reiten, } \\
2015\end{array}$ & $\begin{array}{l}\text { Evaluation of a treatment } \\
\text { strategy }\end{array}$ & Norway & Quantitative & $x$ & 12 & $\begin{array}{l}\text { Adolescen } \\
\mathrm{t}\end{array}$ & Good \\
\hline $\begin{array}{l}\text { Landmark et } \\
\text { al., } 2016\end{array}$ & $\begin{array}{l}\text { Chronic fatigue syndrome } \\
\text { and experience with the } \\
\text { Lightning Process }\end{array}$ & Norway & Survey & PR & 196 & All & Fair \\
\hline $\begin{array}{l}\text { Kristoffersen et } \\
\text { al., } 2016\end{array}$ & $\begin{array}{l}\text { Use of complementary } \\
\text { and alternative medicine } \\
\text { in patients with health } \\
\text { complaints attributed to } \\
\text { former dental amalgam } \\
\text { fillings }\end{array}$ & Norway & Survey & PR & 324 & $\begin{array}{l}\text { Not } \\
\text { reported }\end{array}$ & Good \\
\hline $\begin{array}{l}\text { Crawley et al., } \\
2017\end{array}$ & $\begin{array}{l}\text { Clinical and cost- } \\
\text { effectiveness of the } \\
\text { Lightning Process in } \\
\text { addition to specialist } \\
\text { medical care for } \\
\text { paediatric chronic fatigue } \\
\text { syndrome: randomised } \\
\text { controlled trial }\end{array}$ & UK & $\begin{array}{l}\text { Randomise } \\
\text { d Controlled } \\
\text { Trial }\end{array}$ & $\mathrm{PR} / \mathrm{C}$ & 100 & $\begin{array}{l}\text { Adolescen } \\
\mathrm{t}\end{array}$ & Good \\
\hline
\end{tabular}

Results

\section{Structure of the review}

The reviewed studies were categorised as; (1) qualitative studies and case reports; (2) quantitative surveys and (3) quantitative non-survey studies. Guidance on synthesising the results of systematic reviews involving a complex range of un-uniform study designs led to the utilisation of a narrative and a descriptive presentation of the results framed by these categories in chronological order.20,32

\section{Studies' design and methodology}

All the studies were undertaken in the UK and/or Norway between 2010 and 201819,19,33 (Table 2). The sample sizes ranged from five, in the report from Fønnebø, Dragset \& Salamonsen34 to 4217 in the study from the ME Association.19 Four studies focused on young people/adolescents, four included participants from all age ranges, two studies focused on adults and four did not 
specify age ranges. In all of these studies that reported, gender there were more female than male participants. For studies involving CFS/ME the range reported was from $76 \% 35$ to $95 \% 4$ females. This skewed gender representation was also found in the other studies, although to a lesser degree with $71 \%$ for the study from Kristoffersen et al., 36 67\% for the study from Finch 37 and $58 \%$ for the study from Hagelsteen \& Moen Reiten.38 Race distribution was not reported in any of the studies, with the exception of those related to the RCT from Crawley et al.,18 where participants identified themselves as British.

\section{Qualitative studies}

Sandaunet \& Salamonsen, 2012. A qualitative study of CFS/ME patients' different experiences with Lightning Process recruited participants via the Norwegian National Research in Complementary and Alternative Medicine (NAFKAM) and their Registry of Exceptional Illness (RESF) .4 The participants ( $N=22,95 \%$ female) self-reported 10-26 months after the LPcourse that they had experienced:

1)

Significant improvement $(n=13)$

2)

No response $(n=6)$

3)

Adverse response $(n=3)$

Responses were analysed using a grounded theory-based process. Three themes of differentiation emerged; "(a) the response to the theoretical basis and the basic principles of the LP (b) experiences of course leader and (c) the body's response to the LP" $.4(\mathrm{p} 1)$ The study identified that trust and communication were important. Those reporting an initial positive response to the LP expressed that they had a greater insight into their illness, that they could trust their trainer and that the positive physical effect of the LP continued after the seminar. These factors were not seen with the other respondents.

Fønnebø et al., 2012. The NAFKAM institute instigated a protocol in December 2011 to create a warning notice for health authorities if they received three negative reports for an alternative treatment from patients with the same condition.39 As a result, they reported that three patients with CFS/ME had described how they experienced a strong relapse of their symptoms 6 to 12 months after LP, which they all related to the seminar.34 
Reme, Archer \& Chalder, 2012. A qualitative study evaluated the experiences of nine young people (female $=89 \%$, age range $14-26$ ), who had undergone the LP to treat CFS/ME. 40 The opportunistic sample was recruited through the website Association of Young People with ME (AYME) in the UK and data were collected by semi-structured interviews.

Seven adolescents reporting being satisfied and were much or very much better, and two reported lack of satisfaction and absence of improvement.

Helpful aspects of the approach reported included; the theoretical rationale behind the intervention, the techniques they learned and the practical exercises. Less helpful aspects reported were the short duration and intensity of the LP and little follow-up and, for some, the perceived secrecy surrounding the LP. The study noted how the requirement that participants apply the LP tools as a route to recovery was experienced as a sense of being blamed for lack of change by the two participants who noticed no benefit from the intervention.

Crawley et al., 2013. A pilot randomised trial $(N=56$, female $=76.4 \%$, mean age $=14.8$ years $(S D=1.6)$, age range $12-18)$ was undertaken in the UK to evaluate feasibility and acceptability of the recruitment, randomisation and intervention. 35 The study used an integrated qualitative methodology and found that recruitment, randomisation and interventions were feasible and acceptable. Several changes were suggested by participants to improve the experience and value of taking part in the study. These included more appropriate data collection measures (Chalder Fatigue Scale41) and SF-36 physical function subscale, 42 rather than school attendance and data collection by phone calls.

\section{Quantitative surveys}

Finch, 2010. A survey, carried out in the UK and Norway, evaluated experiences of the LP intervention at the end of the third day of the seminar33 ( $N=1297$, female $=78.5 \%$. Reported issues: ME/CFS $84 \%$, depression $34 \%$, anxiety $56 \%$, low self-esteem $57 \%$, guilt $43 \%$ ).

Results for the question 'Did you get the changes you wanted?' are in Table 3. $0.2 \%$ of the respondents reported that they still had issues because the training was 'not good enough or was inappropriate for their needs'.

Table 3. Did you get the changes you wanted? Score your answer out of 10 $(0=$ definitely no, 10 = definitely yes $)$.

$\begin{array}{llllllllllll}\text { Score Given } & \mathbf{0} & \mathbf{1} & \mathbf{2} & \mathbf{3} & \mathbf{4} & \mathbf{5} & \mathbf{6} & \mathbf{7} & \mathbf{8} & \mathbf{9} & \mathbf{1 0} \\ \text { No. of respondents } & 0 & 1 & 0 & 11 & 10 & 32 & 39 & 94 & 188 & 223 & 683\end{array}$


ME Association, 2010. A UK based charity survey ( $\mathrm{N}=4217$, female $=78 \%$ age range 11-66), asked respondents about their experiences of managing their ME.19 Perceptions of using 25 different approaches, including standard approaches, such as Cognitive Behavioural Therapy (CBT) $(n=997)$, Graded Exercise Therapy (GET) $(n=906)$ and the LP (which was the third least used of the approaches, $n=101$ ) were rated on a Likert scale.

The survey found that the LP received the highest percentage out of all the 25 approaches for those feeling they had 'greatly improved'. A summary of the reported results is presented in Table 4.

Table 4. Results of ME Association Survey, 2010.

\section{Category}

Greatly

Improved

Improved

No Change

Worse

Much

$$
\text { LP }(n=101)
$$

Intervention

$\begin{array}{lll}25.7 \% & 2.8 \% & 3.4 \% \\ 18.8 \% & 23.1 \% & 18.7 \% \\ 34.7 \% & 54.6 \% & 21.4 \% \\ 7.9 \% & 11.6 \% & 23.4 \% \\ 12.9 \% & 7.9 \% & 33.1 \%\end{array}$

Sussex \& Kent ME/CFS Society, 2010. Brighton \& Sussex Medical School and the Sussex \& Kent ME/CFS Society evaluated the experiences of 457 with CFS (mild $29 \%$, moderate $54 \%$, severe $16 \%$, very severe $1 \%$; female $77 \%$; n surveys sent $=900) .43$ Respondents categorised 16 treatments as 'very helpful', 'reasonably helpful' or 'not at all helpful'. The LP received the highest percentage out of all the approaches in the 'very helpful' category and a summary of the reported results is presented in Table 5.

Table 5. Results of Sussex \& Kent ME/CFS Society Survey, 2010.

\begin{tabular}{ll} 
Category & \multicolumn{2}{c}{ Intervention } \\
& LP CBT GET \\
Very helpful & $44 \% 24 \% 12 \%$ \\
Reasonably & $36 \% 50 \% 51 \%$ \\
helpful & 51 . \\
Not at all helpful & $20 \% 26 \% 37 \%$
\end{tabular}

Bringsli et al., 2013. The Norwegian ME Association surveyed members and visitors to its website ( $N=1096,85 \%$ female, age range $11-80+$ ). One question requested the reported effects of 18 interventions, 44 using a Likert scale. $A$ summary of the reported results is presented in Table 6.

Table 6. Results of Norwegian ME Association Survey, 2013. 


\begin{tabular}{llll} 
Category & \multicolumn{3}{c}{ Intervention } \\
Greatly & LP $(\boldsymbol{n}=\mathbf{1 6 6})$ & CBT $(\boldsymbol{n}=\mathbf{3 6 8})$ & GET $(\boldsymbol{n}=\mathbf{3 2 8})$ \\
Improved & $8 \%$ & $2 \%$ & $1 \%$ \\
Improved & $13 \%$ & $13 \%$ & $13 \%$ \\
No Change & $30 \%$ & $63 \%$ & $20 \%$ \\
Worse & $22 \%$ & $14 \%$ & $41 \%$ \\
Much Worse & $27 \%$ & $8 \%$ & $25 \%$
\end{tabular}

Kristoffersen et al., 2016. This study evaluated the "use of complementary and alternative medicine in those with health complaints attributed to former dental amalgam fillings' 36 using data from the Norwegian Dental Patient Association (NDPA) $(\mathrm{N}=324$, female $=71.6 \%)$ and includes reported responses to the LP $(n=16)$, with six reporting good effect, seven reporting no change, none reporting a worsening and three non-responders.

Landmark et al., 2016. A call for research45 published in the Journal of the Norwegian Medical Association reported on a survey evaluation of participants ( $N=196$, age range 10-76) attending the LP in 2008.46 Data collected through phone interviews used a structured questionnaire. The majority of participants reported increased activity level (from 3 to 7 on a Likert scale from 1 to 10 , where 10 is normal/high level of activity), school and work attendance (from $17 \%$ to $60 \%$ ), time in bed/sofa (from $15 \mathrm{~h}$ to $10 \mathrm{~h}$ per day) and better life quality (from 3 to 7 on a Likert scale from 1 to 10 , where 10 is best). The improvement, compared to baseline, lasted more than a year after the LP. There were no reports of serious adverse effects.

\section{Quantitative studies (non-survey)}

Finch, 2013. An interim report was published on an outcome measures, crosssectional study of LP participants $47(\mathrm{~N}=205$, female $=80 \%$, mean age $=37.4$ years (SD = 15.6), age range 9-73) using RAND SF-36.42 The most frequent self-reported reasons for attendance were CFS/ME (64.4\%), anxiety/depression disorders (17.1\%), Multiple Sclerosis (2.9\%) and Fibromyalgia (2.9\%). Repeated measures ANOVA using Time of Testing (three levels; pre-test, six weeks, three months) were used to analyse: health change, physical functioning, role limitations due to physical health, role limitations due to emotional problems, energy/fatigue, emotional well-being, social functioning, pain and general health. The participants reported a significant difference in all sub-scales of RAND SF$36(p<.0001)$ indicating that the LP is associated with positive change on all dimensions of health tested by RAND SF-36. The significant improvement in 
health status persisted in all scales, except the emotion-related measures, at six weeks and three months $(p<.0001)$.

Finch, 2014. A proof of concepts study in conjunction with the Multiple Sclerosis Research Council (MSRC) evaluated if the LP could improve outcomes for those with MS.37 Participants $(N=11$, female $=7)$ were recruited by MSRC in the UK. RAND SF36,42 Functional Assessment of MS scale (FAMS) 48 and Fatigue Severity Scale (FSS) 49 questionnaires were completed at four time intervals: prior to and six weeks, three and six months after attending the LP seminar. Seven participants remained in the study at the six-month stage, and as a result, missing data were excluded from the analysis. Analysis showed improvements in all sub-scales of the RAND SF-36 at all data collection points, with energy/fatigue levels, general health, role limitations due to emotional problems and emotional well-being showing the greatest change. The MSRC commented that, although the study was of a small scale the results indicated that the LP provides measurable benefits to those with MS.50

Hagelsteen \& Moen Reiten, 2015. A small-scale treatment evaluation of adolescents (14-18 years) with chronic headaches $(N=12$, female $=7)$ was undertaken in Norway. 38 Pain levels were evaluated using the Visual Analogue Scale51 and analysis showed that pain was significantly reduced for nine of the participants at three months and this change was maintained at 12 months. The majority also had improved quality of life, were more active and more able to spend time with friends and there was a significant increase in school attendance. The number of participants 'always / almost always in school' had increased from three prior to the LP to eight at one-year post LP.

Crawley et al., 2017. The Specialist Medical Intervention and Lightning Evaluation (SMILE) RCT ( $N=100)$ run by the UK's NHS and University of Bristol compared Specialist Medical Care (SMC) $(n=49)$ to SMC plus LP $(n=51) .18$ SMC comprised a range of approaches including sleep and activity management, CBT for anxiety and low mood and GET. 12-18 year olds (mean age $=14,76 \%$ female) with mild/moderate CFS/ME were recruited for the study. The study found those receiving SMC plus LP had improved physical function at six months compared to those receiving SMC, with an adjusted difference in means 12.5 [95\% Cl 4.5, 20.5], $p=.003$ ), and at 12 months this had increased to $15.1(95 \% \mathrm{Cl} 5.8,24.4, p=.002)$. Those in the SMC plus LP had a greater reduction of anxiety symptoms measured by both the Hospital Anxiety and Depression Scale (HADS)52 $(-3.3,[95 \% \mathrm{Cl}-5.6,-1.0], \mathrm{p}=.005)$ and the Spence Children's Anxiety Scale (SCAS) $53(-8.7,[95 \% \mathrm{Cl}-16.9,-0.5], p=.039)$ 
at six months, and that continued at 12 months. Results also showed a reduction in depression in participants in the SMC plus LP arm compared to those in the SMC arm at 12 months (adjusted difference in means in HADS depression score $-1.7[95 \% \mathrm{Cl}-3 \cdot 3,-0 \cdot 2] \mathrm{p}=.030)$. Pain scores were reduced in participants receiving SMC plus LP compared with those receiving SMC at both six and 12 months, but confidence intervals were wide and unreported. Those in the SMC plus LP arm had improved school attendance at 12 months compared to those receiving SMC (adjusted difference in means 0.9 days of school per week [95\% $\mathrm{Cl} 0.2,1.6] \mathrm{p}=.018$ ). Additionally, it reported evidence that combining SMC with LP was more cost-effective than delivering SMC on its own. This considered the reduced costs of using the NHS as a result of improvement (which was not shown by the study) and increase in health-related quality of life (which was shown by the study), measured by QALYs, derived from the EQ-5D-Y.54 Although nine participants reported a worsening of symptoms at six months (eight in SMC arm, one in SMC + LP arm), five of these nine had deterioration of $\leq 10$ on the SF-36 physical function subscale (range $0-100$ ) which is considered to be less than the minimal clinically important difference. Notability none of the participants in the SMILE trial had any serious adverse events attributable to receiving either SMC or SCM plus LP, which is a valuable finding for assessing benefits to risk ratios.

In January 2018 the journal editors were contacted with concerns that the paper 'lacked sufficient detail and clarity for readers to fully understand the study as conducted.' 55 An extensive clarification process was undertaken with the authors to address these concerns. This resulted in the publication of a revised version of the paper with 'extensive clarifications to the study's timeline and methods' 55 which, the editors concluded, addressed the criticisms raised.

\section{Discussion}

This is the first systematic review to evaluate the quality of the evidence base and collate and review the research on the LP. It presents a timeline of the research as the approach moved from one of practice base evidence, through anecdotal case reports to surveys and finally to peer-reviewed studies, culminating in a well-conducted RCT. There are a number of findings that can be drawn from this review; first, the evidence base is in its early stages, with the first studies appearing in 2010 . Second, the quality of the studies has developed with time, with earlier studies being mainly uncontrolled surveys, with potential 
issues of bias and the later studies being of higher quality, with clearer methodology, and in the case of the RCT, randomisation and controlling elements.

\section{Limitations}

The following limitations are recognised in this review. Several databases were searched, however, others that might have been valuable to include, such as Amed, were not included. Although this had the potential to exclude relevant studies, it was considered that the Google and Google Scholar searches would provide adequate access to studies in journals represented by Amed.

To increase the quality of the review, opinion pieces, forum and blog posts, books, newspapers and magazine articles were excluded,56,57 but it could be argued that the addition of non-peer-reviewed studies in this review has the potential to lower the quality of the findings. Issues arose from potential bias in selection of participants, which were acknowledged particularly by the authors of the surveys from the ME charities.19,43,44 Sample sizes, a lack of detail of power calculations and statistical analysis were of concern in selected papers, including the small sample size of three respondents in the NAFKAM report, 34 issues of comparing interventions when the samples sizes for each intervention were different19,44,58 and from high attrition levels, such as Finch's 2014 MS study. The surveys reported participants' experiences at one time point, Finch's 2010 survey, for example, being undertaken shortly after attending the LP, and are thus limited in assessing longevity of effects. Additionally, limitations common to surveys, concerning self-report and lack of information about clarity of diagnosis, 59,60 an issue that is the cause of strong debate in CFS/ME studies,61,62 may affect the quality of the included studies. In the qualitative studies, the positive or negative outcomes were described, as is usual practice, by self-report. As a result, these naturally lack confirmation through validated measures and have the potential to ascribe cause and effect where it may not be appropriate, particularly where the effect is reported 6-12 months after receiving an intervention.4,34 However, it was decided that maintaining an awareness of, and commenting on the research quality, justified their inclusion and in turn increased the comprehensiveness of this review. As with other studies reporting one author (PP) as the originator of the intervention central to the studies being reviewed, the potential for bias was recognised and 
a series of reflexivity procedures as suggested by researchers 63,64 were implemented by the authoring group during all phases of the study to ameliorate this. 65

\section{Outcomes of the LP}

The studies showed that there was a range of participant's responses to the LP. However, the most robust study reported here, the RCT,18 and the non-survey quantitative studies, reported significant outcomes in a range of measures. Additionally, all the studies and surveys in the review identified a level of benefit from the intervention. Given the range of conditions participants presented with, this suggests that the LP has a broad degree of applicability. The studies also suggest that positive outcomes were not experienced by all, and in the qualitative studies and earlier surveys, a worsening was reported by some.4,34,40 However, the RCT18 did not find any adverse events attributed to either the SMC or SMC +LP arm of the trial. Although reports of worsening after treatment is a finding seen in studies on other interventions for CFS/ME, 19,34,66 these reports highlight issues for the LP organisation to reflect on and learn from. These include the reports of issues of practitioner communication, with some participants reporting feeling blamed or instructed to ignore symptoms, $4,34,40$ although a language barrier might be an issue in these two 2012 Norwegian studies, where the seminars were delivered in English to Norwegian speakers. While this sense of blame is counter to published materials on the LP approach, $1,8,67$ it raises issues with communication, or understanding, of the core concepts, which the organisation and practitioners have reportedly have begun, 68 to take action to address. This variability in responses raises important research questions as to why the LP is reported to have a statistically significant effect in a variety of standardised measurements and no change for others.

\section{Clarity about the LP}

The review also notes the variance and accuracy of reporting of the mechanics and aims of the process.4,40,45,69 It is anticipated that the recent paper on the LP hypothesis 1 and the publication of this review will encourage discussion between researchers and those directly involved in the LP to ensure more clarity of description for future studies. 


\section{Conclusion}

In conclusion, this review identified that there is a developing body of evidence supporting the efficacy of the LP for many participants, although it found a range of reported outcomes to the intervention and a variance in the reported descriptions of the mechanics of the approach. There is a variance in the design and quality of the studies, with the more recent studies being of higher quality and better designed than earlier, non-peer-reviewed ones.

Research to date points to the LP as a developing field of interest which potentially provides additional solutions to a range of illnesses with currently poor treatment outcomes. It is also clear that more research is needed with larger populations to 1) identify who would most benefit from the approach, 2) further evaluate its efficacy, ideally by comparing the LP to a single intervention, to identify if the results of the RCT can be replicated on a larger scale and with adult populations and 3) explore the accuracy of its hypothesised mechanisms with a range of biochemical and functional imaging investigations.

\section{Declaration of Competing Interest}

PP declares an interest in the intervention The Lightning Process as its originator; JA declares an historical interest in the Lightning Process as a former practitioner; LDR declares no interest in the subject under study.

Appendix. Supplementary materials

Download : Download spreadsheet (10KB)

\section{References}

1.

P. Parker, J. Aston, F. FinchUnderstanding the Lightning Process approach to CFS/ME; a review of the disease process and the approach J Exp Psychother, 21 (2) (2018), p. 8 https://jep.ro/images/pdf/cuprins_reviste/82_art_2.pdf View Record in ScopusGoogle Scholar

2.

W. Miller, S. RollnickMotivational interviewing: preparing people to change addictive behavior Guilford Press (1991)

Google Scholar 
3.

J. Leeman, M. SandelowskiPractice-based evidence and qualitative inquiry

JNU J Nurs Scholarsh, 44 (2) (2012), pp. 171-179

CrossRefView Record in ScopusGoogle Scholar

4.

A.-.G. Sandaunet, A. SalamonsenCFE-/ME-pasienters ulike erfaringer med Lightning Process

Sykepl Forsk, 7 (3) (2012), pp. 262-268, 10.4220/sykepleienf.2012.0132

CrossRefView Record in ScopusGoogle Scholar

5.

C. Locher, A. Frey Nascimento, I. Kirsch, J. Kossowsky, A. Meyer, J. Gaabls the rationale more important than deception? A randomized controlled trial of open-label placebo analgesia

Pain, 158 (12) (2017), pp. 2320-2328, 10.1097/j.pain.0000000000001012

CrossRefView Record in ScopusGoogle Scholar

6.

M. Richter, C. Schroeter, T. Puensch, et al.Pain-related and negative semantic priming enhances perceived pain intensity

Pain Res Manag, 19 (2) (2014), pp. 69-74, 10.1155/2014/425321

CrossRefView Record in ScopusGoogle Scholar

7.

J.H. Hibbard, J. GreeneWhat the evidence shows about patient activation: better health outcomes and care experiences; fewer data on costs Health Aff (Millwood), 32 (2) (2013), pp. 207-214, 10.1377/hlthaff.2012.1061 CrossRefView Record in ScopusGoogle Scholar

8.

P. ParkerDû: Unlock Your Full Potential With a Word

Nipton Publishing (2011)

Google Scholar

9.

I. KirschResponse Expectancy and the Placebo Effect

International Review of Neurobiology, 138, Elsevier (2018), pp. 81-

93, 10.1016/bs.irn.2018.01.003

ArticleDownload PDFView Record in ScopusGoogle Scholar

10.

11.

H. SelyeThe Stress of Life. Rev. ed

McGraw-Hill (1978)

Google Scholar

P. Grossman, L. Niemann, S. Schmidt, H. WalachMindfulness-based stress reduction and health benefits: a meta-analysis

J Psychosom Res, 57 (1) (2004), pp. 35-43, 10.1016/S0022-3999(03)00573-7 ArticleDownload PDFView Record in ScopusGoogle Scholar

12.

J.H. WiseThe S.T.O.P. Sign Technique

Fam J, 10 (4) (2002), pp. 433-436, 10.1177/106648002236764

CrossRefView Record in ScopusGoogle Scholar

13.

A. Aldao, S. Nolen-Hoeksema, S. SchweizerEmotion-regulation strategies across psychopathology: a meta-analytic review

Clin Psychol Rev, 30 (2) (2010), pp. 217-237 
https://doi.org/10.1016/j.cpr.2009.11.004

14.

ArticleDownload PDFView Record in ScopusGoogle Scholar

K.D. Neff, K.L. Kirkpatrick, S.S. RudeSelf-compassion and adaptive psychological functioning

J Res Personal, 41 (1) (2007), pp. 139-154

https://doi.org/10.1016/j.jrp.2006.03.004

ArticleDownload PDFView Record in ScopusGoogle Scholar

F.B. Bryant, C.M. Smart, S.P. KingUsing the Past to Enhance the Present: boosting Happiness Through Positive Reminiscence

J Happiness Stud, 6 (3) (2005), pp. 227-260, 10.1007/s10902-005-3889-4

CrossRefView Record in ScopusGoogle Scholar

S. HamannCognitive and neural mechanisms of emotional memory

Trends Cogn Sci, 5 (9) (2001), pp. 394-400, 10.1016/S1364-6613(00)01707-1

ArticleDownload PDFView Record in ScopusGoogle Scholar

17.

18.

J.I. Davis, A. Senghas, F. Brandt, K.N. OchsnerThe effects of BOTOX

injections on emotional experience

Emotion, 10 (3) (2010), p. 433

CrossRefView Record in ScopusGoogle Scholar

E. Crawley, D. Gaunt, K. Garfield, et al.Clinical and cost-effectiveness of the Lightning Process in addition to specialist medical care for paediatric chronic fatigue syndrome: randomised controlled trial Arch Dis Child, 103 (2018), pp. 155-164, 10.1136/archdischild-2017-313375 CrossRefView Record in ScopusGoogle Scholar

19.

ME AssociationManaging My M.E

ME Association (2010)

Accessed March 15, 2018

http://www.meassociation.org.uk/wp-content/uploads/2010/09/2010-survey-

report-lo-res10.pdf

Google Scholar

20.

J. Popay, H. Roberts, A. Sowden, et al.Guidance on the conduct of narrative synthesis in systematic reviews

Prod ESRC Methods Programme Version, 1 (2006), p. b92

Google Scholar

21.

University of YorkPROSPERO International prospective register of systematic reviews

Published online (2015)

Accessed August 13, 2018

https://www.crd.york.ac.uk/prospero/

Google Scholar

22.

D. Moher, A. Liberati, J. Tetzlaff, D.G. AltmanPreferred reporting items for systematic reviews and meta-analyses: the PRISMA statement

BMJ, 339 (2009), p. b2535, 10.1136/bmj.b2535

CrossRefView Record in ScopusGoogle Scholar 
23.

24.

E. Nourbakhsh, R. Nugent, H. Wang, C. Cevik, K. NugentMedical literature searches: a comparison of PubMed and Google Scholar

Health Inf Libr J, 29 (3) (2012), pp. 214-222, 10.1111/j.1471-

1842.2012.00992.x

CrossRefView Record in ScopusGoogle Scholar

S.Z. Shariff, S.A. Bejaimal, J.M. Sontrop, et al.Retrieving clinical evidence: a Comparison of PubMed and Google scholar for quick clinical searches J Med Internet Res, 15 (8) (2013), 10.2196/jmir.2624

Google Scholar

25.

26.

M. Dixon-Woods, D. Cavers, S. Agarwal, et al.Conducting a critical interpretive synthesis of the literature on access to healthcare by vulnerable groups

BMC Med Res Methodol, 6 (2006), p. 35, 10.1186/1471-2288-6-35

Google Scholar

S.H. Downs, N. BlackThe feasibility of creating a checklist for the assessment of the methodological quality both of randomised and nonrandomised studies of health care interventions

J Epidemiol Community Health, 52 (6) (1998), pp. 377-

384, 10.1136/jech.52.6.377

CrossRefView Record in ScopusGoogle Scholar

27.

J.M. Hootman, J.B. Driban, M.R. Sitler, K.P. Harris, N.M. CattanoReliability and validity of three quality rating instruments for systematic reviews of observational studies

Res Synth Methods, 2 (2) (2011), pp. 110-118, 10.1002/jrsm.41

CrossRefView Record in ScopusGoogle Scholar

28.

A. Jarde, J.-.M. Losilla, J. Vives, F. Rodrigo MQ-Coh: a tool to screen the methodological quality of cohort studies in systematic reviews and meta-analyses

Int J Clin Health Psychol, 13 (2) (2013), pp. 138-146, 10.1016/S16972600(13)70017-6

ArticleDownload PDFView Record in ScopusGoogle Scholar

29.

J. Thomas, A. HardenMethods for the thematic synthesis of qualitative research in systematic reviews

BMC Med Res Methodol, 8 (2008), p. 45, 10.1186/1471-2288-8-45

CrossRefView Record in ScopusGoogle Scholar

30.

A.F. Long, M. GodfreyAn evaluation tool to assess the quality of qualitative research studies

Int J Soc Res Methodol, 7 (2) (2004), pp. 181-

196, 10.1080/1364557032000045302

View Record in ScopusGoogle Scholar

31.

National Heart Lung and Blood Institute. Study Quality Assessment Tools. Published 2014. Accessed May 2, 2017. https://www.nhlbi.nih.gov/healthtopics/study-quality-assessment-tools 


\section{Google Scholar}

E. Ahn, H. KangIntroduction to systematic review and meta-analysis Kor J Anesthesiol, 71 (2) (2018), pp. 103-112, 10.4097/kjae.2018.71.2.103 CrossRefView Record in ScopusGoogle Scholar

Finch F. LP Snapshot Survey for Clients; 2010. Accessed July 16, 2013.

DOI: 10.13140/RG.2.2.23107.35366

Google Scholar

V. Fønnebø, B.J. Drageset, A. SalamonsenWorst cases reported to the NAFKAM international registry of exceptional courses of disease Glob Adv Health Med, 1 (1) (2012), p. 30, 10.7453/gahmj.2012.1.1.008 View Record in ScopusGoogle Scholar

E. Crawley, N. Mills, L. Beasant, et al.The feasibility and acceptability of conducting a trial of specialist medical care and the Lightning Process in children with chronic fatigue syndrome: feasibility randomized controlled trial (SMILE study)

Trials, 14 (1) (2013), p. 415, 10.1186/1745-6215-14-415 CrossRefGoogle Scholar

A.E. Kristoffersen, F. Musial, H.J. Hamre, et al.Use of complementary and alternative medicine in patients with health complaints attributed to former dental amalgam fillings

BMC Complement Altern Med, 16 (2016), p. 22, 10.1186/s12906-016-0996-1 Google Scholar

Finch F. MS Proof of Concept Study; 2014. Accessed June 5, 2018.

DOI: 10.13140/RG.2.2.26462.79686

Google Scholar

J.H. Hagelsteen, I.M. Moen ReitenEvaluation of a treatment strategy

Dagens Med (2015)

Published online October 12Accessed November 26, 2015

http://www.dagensmedisin.no/artikler/2015/10/12/evaluering-av-en-

behandlingsstrategi/

Google Scholar

NAFKAM. Nafkam warning note. Published online

2011. https://uit.no/Content/279128/RESF,\%20varsel\%20LP\%2023122011.pdf Google Scholar

40.

S.E. Reme, N. Archer, T. ChalderExperiences of young people who have undergone the Lightning Process to treat chronic fatigue syndrome/myalgic encephalomyelitis - a qualitative study Br J Health Psychol, 18 (3) (2012), pp. 508-525, 10.1111/j.20448287.2012.02093.x Google Scholar

T. Chalder, G. Berelowitz, T. Pawlikowska, et al.Development of a fatigue scale 
J Psychosom Res, 37 (2) (1993), pp. 147-153, 10.1016/0022-3999(93)90081$P$

42.

ArticleDownload PDFView Record in ScopusGoogle Scholar

J.E. Ware, C.D. SherbourneThe MOS 36-item short-form health survey (SF-36). I. Conceptual framework and item selection

Med Care, 30 (6) (1992), pp. 473-483

http://dx.doi.org/10.1097/00005650-199206000-00002

CrossRefView Record in Scopus Google Scholar

43.

Sussex \& Kent ME/CFS Society. Sussex and Kent report. 2010. Accessed October 30, 2018. https://lightningprocess.com/research/

Google Scholar

44.

45.

46.

47.

48.

G.J. Bringsli, A. Gilje, B.K.G. WoldME-syke i Norge - Fortsatt bortgjemt Norges ME-forenlng (2013)

http://www.me-foreningen.info/wp-content/uploads/2016/09/ME-Nat-

Norwegian-Survey-Abr-Eng-Ver.pdf

Google Scholar

L. Landmark, R.M.B. Lindgren, B. Sivertsen, et al.Chronic fatigue syndrome and experience with the Lightning Process

Tidsskr Den Nor Legeforening, 136 (5) (2016), 10.4045/tidsskr.15.1214

396-396

Google Scholar

Aktiv Prosess. Deltakerevaluering-Uten-Diagnoser.Pdf.; 2016. Accessed

October 31, 2018. https://www.livelandmark.no/wp-

content/uploads/2011/11/Deltakerevaluering-uten-diagnoser.pdf

Google Scholar

Finch F. Outcomes Measures Study; 2013. Accessed June 5, 2018.

DOI: 10.13140/RG.2.2.29818.24002

Google Scholar

A.M. Yorke, E.T. CohenFunctional Assessment of Multiple Sclerosis J Physiother, 61 (4) (2015), p. 226, 10.1016/j.jphys.2015.05.021 ArticleDownload PDFView Record in ScopusGoogle Scholar

49.

L.B. Krupp, L.A. Alvarez, N.G. LaRocca, L.C. ScheinbergFatigue in Multiple Sclerosis

Arch Neurol, 45 (4) (1988), pp. 435-

437, 10.1001/archneur.1988.00520280085020

CrossRefView Record in ScopusGoogle Scholar

50.

P. ParkerAn Introduction to the Lightning Process $\AA$ : The First Steps to Getting Well

Hay House (2012)

Google Scholar

51.

D.D. Price, P.A. McGrath, A. Rafii, B. BuckinghamThe validation of visual analogue scales as ratio scale measures for chronic and experimental 
pain

Pain, 17 (1) (1983), pp. 45-56, 10.1016/0304-3959(83)90126-4

ArticleDownload PDFCrossRefView Record in ScopusGoogle Scholar

52.

R.P. Snaith, A.S. ZigmondThe hospital anxiety and depression scale

Br Med J Clin Res Ed, 292 (6516) (1986), p. 344

https://doi.org/10.1136/bmj.292.6516.344

CrossRefView Record in ScopusGoogle Scholar

53.

54.

S.H. SpenceA measure of anxiety symptoms among children

Behav Res Ther, 36 (5) (1998), pp. 545-566, 10.1016/S0005-7967(98)00034-5

ArticleDownload PDFView Record in ScopusGoogle Scholar

U. Ravens-Sieberer, N. Wille, X. Badia, et al.Feasibility, reliability, and validity of the EQ-5D-Y: results from a multinational study

Qual Life Res, 19 (6) (2010), pp. 887-897, 10.1007/s11136-010-9649-x

CrossRefView Record in ScopusGoogle Scholar

55.

N. BrownEditor's note on correction to Crawley et al. (2018)

Arch Dis Child, 104 (10) (2019), 10.1136/archdischild-2017-313375ednote

e3-e3

Google Scholar

56.

57.

T. McGinn, B. Taylor, M. McColgan, J. McQuilkanSocial work literature searching: current issues with databases and online search engines Res Soc Work Pract, 26 (3) (2016), pp. 266-277, 10.1177/1049731514549423 CrossRefView Record in ScopusGoogle Scholar

M. Sampson, J. McGowan, E. Cogo, J. Grimshaw, D. Moher, C. LefebvreAn evidence-based practice guideline for the peer review of electronic search strategies

J Clin Epidemiol, 62 (9) (2009), pp. 944-952, 10.1016/j.jclinepi.2008.10.012

ArticleDownload PDFView Record in ScopusGoogle Scholar

58.

59.

Sussex \& Kent ME/CFS SocietyPacing Helps ME

Sussex \& Kent ME/CFS Society (2010)

Published 2010. Accessed June 5, 2018

http://measussex.org.uk/pacing-helps-me-2010/

Google Scholar

X. Fan, B.C. Miller, K.-.E. Park, et al.An exploratory study about inaccuracy and invalidity in adolescent self-report surveys

Field methods, 18 (3) (2006), pp. 223-244, 10.1177/152822×06289161

CrossRefView Record in ScopusGoogle Scholar

60.

K.M. Mazor, B.E. Clauser, T. Field, R.A. Yood, J.H. GurwitzA demonstration of the impact of response bias on the results of patient satisfaction surveys

Health Serv Res, 37 (5) (2002), pp. 1403-1417, 10.1111/1475-6773.11194 View Record in ScopusGoogle Scholar

61.
A. Avellaneda Fernández, Pérez Martín Á, M. Izquierdo Martínez, et 
al.Chronic fatigue syndrome: aetiology, diagnosis and treatment

BMC Psychiatry, 9 (1) (2009), p. S1, 10.1186/1471-244X-9-S1-S1

View Record in ScopusGoogle Scholar

62.

M. Horton-SalwayThe 'ME Bandwagon' and other labels: constructing the genuine case in talk about a controversial illness

Br J Soc Psychol, 46 (4) (2007), pp. 895-914, 10.1348/014466607×173456

View Record in ScopusGoogle Scholar

63.

Curzer HJ, Santillanes G. Managing conflict of interest in research: Some suggestions for investigators. Account Res. 2012;19(3):143-

155. https://doi.org/10.1080/08989621.2012.678685

Google Scholar

64.

65.

Rhodes T, Coomber R. Qualitative methods and theory in addictions research. In: Miller PG, Strang J, Miller PM, eds. Addiction Research Methods. WileyBlackwell; 2010:59-78. https://doi.org/10.1002/9781444318852.ch5.

Google Scholar

Pannucci CJ, Wilkins EG. Identifying and avoiding bias in research. Plast Reconstr Surg. 2010;126(2):619-

625. https://doi.org/10.1097/PRS.0b013e3181de24bc.

Google Scholar

66.

D. Dougall, A. Johnson, K. Goldsmith, et al.Adverse events and deterioration reported by participants in the PACE trial of therapies for chronic fatigue syndrome

J Psychosom Res, 77 (1) (2014), pp. 20-26, 10.1016/j.jpsychores.2014.04.002 ArticleDownload PDFView Record in ScopusGoogle Scholar

67.

68.

P. ParkerGet the Life You Love, Now: How to Use the Lightning Process $₫$ Toolkit for Happiness and Fulfilment

Hay House (2013)

Google Scholar

P. ParkerSummary and Response to: Experiences of Young People Who Have Undergone the Lightning Process to treat Chronic Fatigue Syndrome/Myalgic Encephalomyelitis. A qualitative study

Lightning Process (2012)

Accessed June 15, 2018 http://lightningprocess.com/wp-

content/uploads/2018/06/Health-Psych-article-Summary-and-Response-

20.09.20121.pdf

Google Scholar

69.

E. Crawley, N. Mills, W. Hollingworth, et al.Comparing specialist medical care with specialist medical care plus the Lightning Process $₫$ for chronic fatigue syndrome or myalgic encephalomyelitis (CFS/ME): study protocol for a randomised controlled trial (SMILE Trial)

Trials, 14 (2013), p. 444, 10.1186/1745-6215-14-444

CrossRefGoogle Scholar 